\title{
O ACERVO DOCUMENTAL E INVENTÁRIO DE OBRAS DO MUSEU DE ARTE DA PAMPULHA, POSSIBILIDADES DE ESCRITA DA HISTÓRIA DA ARTE
}

Nelyane Gonçalves Santos I

Rodrigo Vivas Andrade2

DOI: https://doi.org/ 0265 I 2/museologia.v7i | 4 . 18398

\section{RESUMO}

A organização de fontes documentais relacionadas à arte contribuem nas pesquisas sobre as obras e na identificação de perfis de acervos e coleções, sendo fundamental na escrita da história da arte. Assim, o grupo de pesquisa Memória das Artes Visuais desenvolveu a sistematização de fontes do Inventário do Museu da Pampulhal e dos Salões de Arte de Belo Horizonte

\section{PALAVRAS-CHAVE}

Acervo Documental, Inventário Museu de Arte da Pampulha, Salões de Arte de Belo Horizonte, História da Arte, Memória

\begin{abstract}
THE DOCUMENTARY COLLECTION AND INVENTORY OF WORKS OF THE PAMPULHA ART MUSEUM, WRITING POSSIBILITIES OF THE HISTORY OF ART
\end{abstract}

\section{ABSTRACT}

The organization of documentary sources related to art contributes in the research on works and in the identification of profiles of collections, being fundamental in the history of the art. Thus, the research group Memória das Artes Visuais developed a systematization of sources of the Inventory of Museu da Pampulha and the Salons of Art of Belo Horizonte.

\section{KEY-WORDS}

Documentary Collection, Inventory of Pampulha Art Museum, Belo Horizonte Art Salons, Art history, Memory

\footnotetext{
' Livro organizado pelo próprio Museu contendo todas as obras que fazem parte de seu acervo, adquiridas até 2010 e suas respectivas informações.

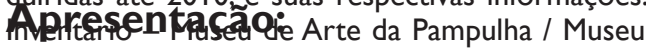
de Arte da Pampulha. - Belo Horizonte: Museu de e de outros profissionais da área, a coleta

' Doutoranda em Artes pela EBA/UFMG. Mestra em Artes pela EBA/UFMG. Bacharel em Conservação e Restauração pela EBA/UFMG. Licenciatura em História pela FAFICH/UFMG. Atua em pesquisas sobre história da arte no Brasil e salões de arte na década de 1960

2 Doutor em História da Arte pela UNICAMP (2008). Mestre em História da Cultura pela FAFICH/UFMG (200I). Graduado em História pela UFOP (1999). Professor do Departamento de Arte Plásticas da EBA/ UFMG, professor permanente do Programa de Pós-Graduação em Artes da UFMG.Atualmente é Diretor do Centro Cultural UFMG.
} 
e análise de fontes documentais é fundamental no processo de pesquisa. Conduzido pela análise e diálogos que pretende construir sobre a obra de arte, que é fundamentalmente o seu objeto de pesquisa, esse profissional vai em busca de indícios relacionados à produção, inserção e recepção das obras nos circuitos artísticos. É necessário esclarecer que existem inúmeras possibilidades de pesquisa sobre arte, entretanto, o interesse aqui definido decorre da perspectiva da obra de arte enquanto fonte, sendo que a partir dela é que o historiador da arte trilha seus caminhos investigativos. Diferencia-se, pois, da dinâmica da teoria da estética que trabalha com definições sobre os objetos artísticos. Já o historiador da arte concentra-se nas obras investigando as produções que foram consideradas artísticas em determinado momento.

Nesta perspectiva da pesquisa histórica sobre a arte, apresenta-se neste texto, alguns dos caminhos metodológicos na organização dos vestígios que perpassam a existência das obras. No Brasil, existem inúmeros museus regionais que possuem em seus acervos importantes obras fundamentais para a história da arte. Infelizmente, muitos desses museus não conseguiram levantar, sistematizar, analisar e disponibilizar seus acervos para o público em geral, funções tais que fazem parte de suas atribuições e que motivaram suas construções. No presente texto analisaremos um caso específico: o perfil da coleção do Museu de Arte da Pampulha em Belo Horizonte-MG.Veremos a seguir, o quanto a história da aquisição das obras para o seu acervo é intrínseca à história desta instituição, o que nos leva ao conhecimento de um dos principais eventos promovidos ao longo de sua existência, os Salões de arte.

Os Salões de Arte de Belo Horizonte, promovidos pela Prefeitura Municipal de 1937 a 1997, deixaram para a história da arte brasileira, além de um conjunto de obras, registros documentais, tais como: catálogos, recortes de jornais, fotografias, convites, cartazes, fichas de inscrição de artistas, regulamentos, bilhetes e comunicados oficiais entre os responsáveis, atas de julgamento, caderno de tombo, fichas catalográficas. Todo este acervo documental encontra-se distribuído entre os museus e arquivos públicos da cidade (Museu de Arte da Pampulha, Museu Histórico Abílio Barreto, Arquivo Público da Cidade e Museu Mineiro), estando, em muitos casos, desvinculados das obras e do seu contexto original de produção.

Há um contexto de separação e acondicionamento destas fontes que precisa ser esclarecido e compreendido pelo pesquisador, para que este possa programar-se melhor em seu ofício, assim como evitar enganos e lacunas em sua pesquisa. Esta dispersão torna-se um desafio a mais para a escrita da História da Arte em Belo Horizonte que tende a enfrentar problemas na trama dos vestígios a partir da descoberta do seu local de acesso em primeiro lugar, para posteriormente sistematizar e analisar suas fontes.

O grupo de pesquisa Memória das Artes Visuais em Belo Horizonte (MAV/ $\mathrm{BH})$, inserido nessa trajetória desafiadora de identificação de um corpus documental capaz de decifrar o circuito artístico em que as obras de arte foram produzidas e expostas nos Salões, está desenvolvendo a sistematização e indexação das principais fontes documentais para posteriormente correlaciona-las com as obras e gerarem consultas para pesquisas ${ }^{3}$. Um projeto que surgiu da necessidade de organização definitiva para futuras pesquisas, provocado pela situação lamentável da história da arte brasileira ter poucos acervos disponibilizados aos pesquisadores. Este procedimento atenderá o grupo de pesquisa e aos in-

\footnotetext{
${ }^{3}$ Grupo de Pesquisa do CNPq
} 
teressados, além de proporcionar o diálogo com outras produções referentes às curadorias, museologia e arquivologia, evitando-se enganos, que já foram registrados, no tocante à exposição, datação e atribuição de obras do acervo artístico dos Salões de arte de Belo Horizonte. Este trabalho e as possibilidades que a construção de uma rede de fontes poderá trazer para as pesquisas serão apresentados, acreditando-se que possa contribuir para questionar os marcos estabelecidos por uma história da arte no Brasil, pautados muitas vezes pelo eixo Rio-São Paulo e pelo destaque à biografias de artistas elencados pela crítica ao longo dessa história.

\section{Introdução}

Os Salões Municipais de Belas Artes de Belo Horizonte, com início de realização no Museu da Pampulha em 1957 (ano de sua inauguração), foram exposições anuais de arte financiadas pela Prefeitura. ${ }^{4}$ Foi através desse evento, que o Museu adquiriu grande parte de seu acervo, pela entrega das obras dos artistas premiados, pelos prêmios de aquisição concedidos por empresas colaboradoras (segundo as normas do regulamento) e pelas doações dos artistas participantes. Em publicações anteriores já destacamos a importância do salão pela sua capacidade de movimentação do circuito da cidade afirmando que o concurso incorporava um perfil de instituição museológica, reordenando a classificação dos artistas premiados, sendo um cenário de efervescência da arte na capital mineira ${ }^{5}$. Dessa forma, o evento se tornou grande fonte de pesquisa para, a partir de estudos, conseguirmos traçar características, apontar relevâncias e indícios de uma história da arte em Belo Horizonte.

Sendo o Museu da Pampulha sede dos Salões, reconhece-se a importância de seu Inventário como fonte documental para a realização de pesquisas, uma vez que muitas das obras que fazem parte de seu acervo participaram de alguma maneira do evento. Segundo Nathaly Yassuda:

A documentação museológica representa um dos aspectos da gestão dos museus destinada ao tratamento da informação em todos os âmbitos, desde a entrada do objeto no museu até a exposição.(...) Considerando os documentos como registros da atividade humana, a documentação serve como instrumento de comunicação e preservação da informação no âmbito da memória social e da pesquisa científica. (YASSUDA: 2009: 22)

Em sua dissertação, a autora expõe alguns exemplos de sistemas museológicos a partir de sua documentação, sendo um deles o Sistema de Informação do Acervo Nacional de Belas Artes no Rio de Janeiro. Pode-se perceber a presença de uma complexa base de dados fazendo parte da organização desse Museu que resultam no acesso a maiores informações sobre as obras e viabilizam estudos referentes a elas. Dessa forma, a exemplos de bancos já existentes e que comprovadamente funcionam bem, diante da ausência de ferramentas similares no próprio MAP, empenhamo-nos em organizar uma base de dados que gere possibilidades de acesso às fontes de pesquisas, sistematizando informações que reconheçam aspectos e características sobre o acervo e sobre eventos que lá foram realizados.

Para além da construção de um banco que objetiva auxiliar a escrita sobre a História dos Salões de Belo Horizonte, a busca pela criação de um perfil do

\footnotetext{
${ }^{4} \mathrm{~A}$ exposição anual de arte da Prefeitura Municipal de Belo Horizonte foi inaugurada em 1937 em atendimento à uma demanda dos artistas da cidade. Com algumas pausas e algumas mudanças de nomenclatura e de regulamento, os salões ocorreram até 1997.

${ }^{5}$ VerVIVAS, 2013 e SANTOS, 2015.
} 
acervo do MAP alcança importantes questões relacionadas ao papel social dessa instituição enquanto Museu. Ao notarmos sua situação atual, de problemas comuns a vários museus de arte do país que lutam contra a precariedade das condições de preservação e acesso de seus acervos, e a relação da instituição com as obras dentro do seu espaço, percebemos a urgência em reconhecer sua composição e pensar em um possível e coerente sistema de funcionamento que proporcione melhores condições de pesquisa e visibilidade. Diante disto será possível a criação de um diálogo tanto entre obra e museu como também entre museu e público.

Referente a essa inter-relação, podemos ver a situação do MAP sob três perspectivas, sendo a primeira referente ao museu e o seus discurso institucional. Entre estas duas instâncias há uma interrupção e não uma ligação entre a formulação e a prática discursiva. Isso se comprova pelo fato de que além do Inventário não haver publicações do MAP que se dediquem a identificar suas coleções e respectivas funções e relações dentro do todo do acervo. Desta maneira o discurso institucional e o Museu ocupam lugares distintos e quase opostos.

O segundo caso a ser questionado é decorrente da própria instituição e de sua relação com as obras que fazem parte do acervo. Para caracterizar a situação das peças do Museu, lembremos dois termos de Emerson Dionísio de Oliveira, sendo eles o "objeto-testemunho", ou seja, aquele que assume apenas o "compromisso com a preservação de um dado passado" e o "objeto-diálogo" que a partir de uma visibilidade é capaz de se transformar em canal de comunicação (OLIVEIRA: 2010: 22).A própria função museológica se vê abalada pelo fato de não se materializar as condições de visibilidade às obras. Além do discurso sobre as mesmas ser silenciado pelo confinamento às reservas técnicas, $e$ ficam cerceadas, impossibilitadas de ultrapassarem a condição de "objeto testemunho" e se transporem para a condição de "objeto-diálogo".

Compreendemos aqui a complexidade das limitações existentes na projeção do objeto de pesquisa, ou seja, a obra de arte e todos os vestígios documentais de sua existência, dentro de uma instituição museológica. Percebemos também, que esta enfrenta dificuldades para cumprir o seu papel de incentivadora da construção do conhecimento em seu espaço, a partir de suas exposições e dos diálogos que poderia estabelecer com o público e com os pesquisadores.

Ligada a este segundo caso, ainda existe uma terceira quebra no Museu de Arte da Pampulha, vinculada ao campo de conhecimento da história da arte. Os vazios institucionais na promoção da visibilidade das obras, as afasta da construção da história da arte, pois, sem acesso não há questionamentos que se convertam em pesquisas, consequentemente, não há conhecimento que preencha o vazio do esquecimento, anulando a realidade das obras que constituem o acervo do MAP.É passível de reconhecimento os esforços das equipes institucionais em reafirmar o papel museológico deste Museu, mas ressalta-se sua insuficiência diante da tradição de ausência de políticas públicas de valorização do seu acervo que vem se perpetuando por toda sua história.

Além destes desafios, ligados aos problemas institucionais, outros surgem na trajetória de pesquisa pelo fato de existirem outras fontes que enriquecem o conteúdo de informações para a escrita de uma história da arte na capital de Minas Gerais. Com o acesso ao conteúdo dos catálogos dos Salões e reportagens em diferentes jornais relacionadas ao tema, percebemos que esses textos são de grande valor para o entendimento da constituição do acervo no Museu. Isso acontece devido à narrativa "ao calor do momento", ou seja, o discurso dos jornais é feito simultaneamente aos acontecimentos, possibilidade que oferece uma 
visão mais aproximada das impressões da época e nos distanciam de possíveis interpretações anacrônicas sobre a valorização atribuída às obras posteriormente.

A busca e organização desse conteúdo jornalístico em uma plataforma digital possibilita o surgimento de um novo tipo de memória social. De acordo com Vera Dodebei, em seu artigo Patrimônio e memória digital, “...a passagem acelerada do patrimônio cultural para o território ciberespaço (...) fortalece a discussão sobre a qualidade, a quantidade e a diversidade das informações..." (DODEBEl: 2006: 5). Dessa forma, o Acervo Documental dos Salões do Museu de Arte da Pampulha assegura a preservação da informação e com isso amplia as possibilidades de pesquisa, análise e conhecimento dos fatos e discussões referentes a obras, eventos e artistas.

\section{O Banco de Dados do Museu de Arte da Pampulha}

O Banco de dados do Museu de Arte da Pampulha é uma base criada no programa Access ${ }^{6}$ que recupera todos os dados disponíveis no livro Inventário do MAP. Na apresentação do livro, o diretor da instituição à época, Sérgio Rodrigo Reis, comenta sobre o valor dessa sistematização em que "após um intenso período de preparação que mobilizou, nos últimos anos [2008-2010], boa parte da equipe técnica do Museu, finalmente é possível se precisar a quantidade, a qualidade e as diversas peculiaridades dessa preciosa coleção..." (MAP: 20 10: 7). Segundo Reis, o processo de elaboração do Inventário se tornou revelador, uma vez que foram necessárias inúmeras discussões para a definição de critérios nesta organização:"ao checar com rigor os dados, a equipe técnica do MAP deparou-se com curiosidades sobre os trabalhos, o que a levou a redefinir parâmetros de algumas obras, corrigindo algumas lacunas de catalogações anteriores" (MAP: 2010:7). O objetivo da organização das informações presentes nesse Inventário foi o de contabilizar as obras dessa instituição, conhecer suas principais características e a partir disso oferecer possibilidades para se traçar um panorama sobre o que é este acervo, em termos de perfil e de associações com a sua história de constituição.

Após esse livro de 2010, o MAP não efetivou nenhuma outra publicação de divulgação de seu acervo, não havendo edições oficiais que abordassem pesquisas sobre as obras, apenas catálogos de exposições com comentários pontuais sobre algumas delas. A partir do estudo do Inventário, percebemos a importância de se analisar as características do acervo em função do perfil de aquisição adotado pela instituição ao longo de seus 60 anos de existência.

Segundo Nathaly Yassuda, um "inventário seria o levantamento individualizado e completo dos bens de uma instituição ou pessoa. Nele consta o registro, identificação e classificação" (YASSUDA: 2009: 24). Dessa forma, o Inventário do MAP é um volume composto por 240 páginas divididas entre apresentação, critérios de sistematização, lista de siglas e lista de obras e ficha técnica.A partir dos critérios observa-se que as informações das obras obedecem a seguinte ordem: nome do autor, título da obra, data da obra, material e técnica, dimensões e informações complementares, sendo que todos os itens estão situados à direita da imagem. Há ainda o número de registro da obra que se encontra abaixo da imagem. $O$ inventário também proporciona explicação para cada item mencionado e instruções para situações específicas no registro de cada obra como por exemplo "nos casos de obras sem uma técnica definida, descrevem-se apenas os materiais nelas empregados" (MAP: 2010: 9).

${ }^{6}$ Sistema de gerenciamento de banco de dados da Microsoft. 
Em entrevista para Carlos Siquara no jornal $O$ tempo ${ }^{7}$, a então museóloga do MAP, Ana Paula Portugal, exemplifica uma das consequências dessa iniciativa para o Museu.

Uma consequência interessante desse projeto é notar como o MAP tem sido contemporâneo aos artistas. Sempre houve a preocupação de contemplar os trabalhos produzidos em diferentes épocas. Quando observamos na coleção algumas criações da década de 1960, percebemos que aquelas obras foram adquiridas naquele período. Já havia o interesse em mostrar alguns artistas expoentes. (PORTUGAL apud SIQUARA: 20I I)

No banco de dados, pensado como produto da análise e sistematização das informações do Inventário do MAP, foi pensado uma divisão do conteúdo das informações presentes no livro por itens que atendessem os interesses de pesquisa de maneira a caracterizar o acervo. A partir disso o banco se dividiu entre: código da obra, unidade, tipo de entrada, especificação de entrada, nome do salão, júri do salão, ano de entrada, artista, gênero do artista, ano da obra, título da obra, categoria, técnica e dimensão.

Demos o nome de "código da obra" para a organização numérica que o próprio Museu realizou no Inventário. Junto a esse código observamos em algumas obras abreviaturas e/ou números secundários que especificam o que chamamos de "unidade", como por exemplo se faz parte de uma instalação (INS), de um díptico (seguem-se ao número de registro um ponto, o número da parte, uma barra e o número total de partes), livro de imagem (LIV), álbum (ALB), entre outros. Seguimos com o ano em que a obra começou a fazer parte do MAP e em qual situação esta entrou para o acervo com o "tipo de entrada". Foi preciso especificar em outra coluna este tipo de entrada que possui observações próprias e relevantes.

Outros itens pontuais, não especificados no Inventário, mas logicamente perceptíveis ou de pesquisa segura na internet, também foram acrescentados, tais como o gênero dos artistas e a categoria da obra (entre gravura, escultura, pintura, desenho e algum outro tipo com especificação). $O$ nome do artista, o nome da obra, além de sua data, título e informações relacionadas aos materiais e técnicas das obras e quais suas dimensões seguiram o registro fiel do Inventário. Por mais que as informações de algumas obras nos indicassem prováveis erros, pelo fato de já termos trabalhado em outras pesquisas com algumas delas, as informações fiéis do Inventário foram mantidas porque o intuito era também o de conhecer melhor esse trabalho realizado pelo MAP e o reconhecimento feito pela própria instituição sobre seu acervo. As observações relativas a tais erros foram registradas em separado para prováveis oportunidades de sugestões para reedições do Inventário.

O padrão que se usou referente às produções foi o de "peça”. Esse acordo foi necessário para tentar quantificar as obras, já que a sequência numérica do Inventário leva em conta as partes de obras.Apesar disso, o programa usado nos dá a possibilidade de filtrar informações sendo possível, a partir de tais peças, selecionar apenas um item que sirva como representante da obra.

Inicialmente, a construção do banco se deu apenas por informações referentes às obras que entraram no Museu através dos Salões, atendendo a um interesse imediato de pesquisa do Grupo que precisava constatar se o acervo foi majoritariamente constituído pelas aquisições desses eventos. A partir disso foi possível perceber que no MAP constam 630 produções com entrada entre

\footnotetext{
${ }^{7}$ http://www.otempo.com.br/pampulha/acervo-do-map-em-livro-I.8978.
} 
1957 até 2006 de obras premiadas ou que apenas participaram de alguma forma dos Salões Municipal de Belas Artes de Belo Horizonte - SMBA-BH e dos Salões Nacional de Arte de Belo Horizonte - SNA-BH. Tal número gera um percentual de aproximadamente $47 \%$ do acervo o que demonstra a significativa importância do evento.

À medida que o banco foi se desenvolvendo, outros tipos de entradas foram acrescentadas: aquisição, por integração e incorporação, participação (em eventos diferentes do salão), premiação (em eventos diferentes do salão), doação e transferência. De modo a especificar o item anterior, foi criada uma coluna com observações sobre a entrada da obra no museu, sendo possível notar, por exemplo, o nome de outros eventos diferentes de salão, outras classificações de prêmios, indicações de quem fez alguma doação, etc.

Logo em seguida, a atenção voltou-se para o registro dos gêneros dos artistas, o eu nos levou a constatar que o acervo é composto por, aproximadamente, obras de $68 \%$ artistas homens e $30 \%$ artistas mulheres. Notou-se também a atuação de 13 grupos (coletivo de artistas) responsáveis pela produção das obras.

No que diz respeito aos resultados da organização da base, foi possível criar alguns gráficos e analisar seus resultados. Percebemos, por exemplo, a recorrência dos artistas no acervo por meio dos Salões e destacamos durante a década de 70 o artista Manoel Augusto Serpa, premiado nos anos de 1970, I97I, I972 e 1975. Outros artistas que também se destacam pela quantidade de prêmios adquiridos nesse período foram Maurino Araújo, Inácio Rodrigues de Oliveira, Manfredo Souzanetto e Yukio Suzuki, cada um com um total de três premiações.

Ainda buscando informações sobre a década de 70, notamos que o maior número de obras que contribuíram para o crescimento da coleção do Museu advém desse período. Este percentual é de $33 \%$ e em contrapartida, percebemos que apenas 3\% foram adquiridas na década de 1990, época de menor ingresso de obras no acervo. É importante mencionar ainda que, $31 \mathrm{I}$ obras, $\mathrm{O}$ equivalente a $24 \%$, não possui informação com relação a data de entrada de acordo com o Inventário. Além desse item, outros como o tipo de entrada também não são informados em algumas obras. Ou seja, são aspectos a serem pesquisados posteriormente em fontes documentais com vistas a obtenção de maiores informações.

Outro dado que se notou, foi a porcentagem das categorias de obras que constituem o acervo. No Inventário não há registro de categorias, por essa razão, muitas obras nos oferecem dificuldades para identificação já que são constituídas de diferentes materiais. De acordo com as informações do banco e observando as técnicas mais comuns usadas nas modalidades entre pintura, escultura, desenho e gravura, foi possível concluir, dentro das obras já analisadas, que o número de pinturas e gravuras são os mais representativos dentro do Museu. Mesmo sendo uma instituição considerada de arte moderna e contemporânea essa informação pode estimular questionamentos sobre o papel da arte contemporânea e sua desmaterialização e rompimento com estas categorias dentro do MAP8.

Por fim, com a organização do Inventário do MAP num banco de dados, percebemos que, depois dos Salões, a maior constituição de acervo deste Museu ocorreu por meio de doações. Pelo fato de não haver o registro de compra

${ }^{8}$ A respeito disso, ver dissertação de Joana Alves. ALVES, Joana D'arc de Jesus. Premiações nos Salões de Belo Horizonte: da 'desmaterialização' à realidade do circuito artístico (1969 a 1972). 2015. Dissertação (mestrado) - Universidade Federal de Minas Gerais, Escola de Belas Artes, Belo Horizonte, 2015. 
no Inventário, nesses termos de aquisição via financiamento direto do Museu pela Prefeitura Municipal, não é possível afirmar se a instituição adquiriu obras desta maneira. $O$ que seria outro item de pesquisa demandando consulta à fontes documentais.

A partir do reconhecimento do que há de informações oficiais sobre o acervo do MAP, mesmo que sucintas, há a possibilidade de gerarmos questionamentos para investigações que nos levem a compreender a trajetória de constituição do Museu. Pelas buscas das categorias de informações, podemos traçar perfis de artistas, obras e eventos promovidos, em recortes temporais específicos. Essa importante fonte bibliográfica que é o Inventário do MAP, nos oferece várias possibilidades de cruzamento de informações. Mas a busca por outros vestígios para a compreensão da história da arte em Belo Horizonte nos leva para outros acervos documentais, os quais, a organização, apresentamos a seguir.

\section{O Acervo Documental dos Salões do Museu de Arte da Pampulha}

O Acervo Documental dos Salões de Arte da Prefeitura de Belo Horizonte é organizado a partir de uma plataforma online utilizada para armazenamento de documentos que foram fotografados e armazenados em arquivos digitais. $O$ intuito dessa base de organização é proporcionar consultas mais diretas e objetivas, relacionando mais rapidamente as obras aos respectivos documentos de sua historicidade. $O$ objetivo foi o de contribuir para a agilidade da escrita de artigos, textos acadêmicos, projetos de pes ${ }^{9} q u i s a$ e de curadorias para o Grupo MAV.

Com relação a essa iniciativa, Renata Padilha (20I4), em seu texto “Documentação Museológica e Gestão de Acervo" fala sobre a função do objeto museológico e de sua relação para com as pessoas que trabalham de alguma maneira, junto dele. Ela pontua alguns elementos que estão extremamente relacionados ao sistema de informação de um acervo, tais como, coleta (entrada), manipulação, armazenamento (processo) e disseminação (saída) da informação, fornecendo um mecanismo de retorno e auto avaliação para os museus.

Além do público e dos funcionários do museu, a sistematização do acervo deve atender às necessidades informacionais do pesquisador especializado, que busca no acervo o seu objeto de estudo para a pesquisa científica. Considera-se, dessa forma, que o objeto museológico é uma fonte de informação para a pesquisa, e que, por esse motivo, precisa que sua informação esteja codificada de uma forma que facilite a interoperabilidade. (PADILHA: 20I4: 63).

Visando o alcance do conceito de interoperabilidade ${ }^{10}$ utilizado pela autora, foi necessário recuperar a documentação disponível nas instituições públicas de memória de Belo Horizonte que possuíssem referências aos Salões de Arte municipais. A partir disso seguiram-se algumas etapas no processo de construção do acervo. Foram organizados primeiramente os documentos das décadas de 1960 e 1970, período escolhido devido à maior quantidade de fontes disponíveis e para atender a interesses de pesquisa do Grupo.

A organização foi pensada em quatro diferentes etapas. A primeira fase da metodologia consistiu em fotografar todos os documentos relacionados ao Sa-

\footnotetext{
${ }^{9}$ É importante destacar que a reprodução dos documentos atende única e exclusivamente interesses de pesquisa acadêmica e que para sua realização foram feitas consultas aos atendentes dos órgãos de memória consultados. No caso do APCBH os atendentes realizam uma avaliação da reprodutibilidade dos documentos por fotografias, devido à restrições por direitos autorais à alguns exemplares do acervo.

${ }^{10}$ Esse termo está associado à capacidade de um sistema, seja ele informatizado ou não, de se comunicar de forma clara com outro sistema, podendo esse segundo ser semelhante ao primeiro ou diferente.
} 
lão de Arte de Belo Horizonte presentes no Arquivo Público da Cidade de Belo Horizonte - APCBH, instituição que guarda grande parte do acervo documental.

Em todo o processo de organização de fontes documentais é muito importante levarmos em conta a origem dos documentos e a maneira como os mesmos foram arquivados. Nos interessa saber como e por que chegou-se ao conteúdo de tais documentos, tanto nas motivações para sua produção quanto para sua guarda. No caso dos documentos relativos aos Salões de Arte de Belo Horizonte, sua origem está diretamente vinculada à direção do Museu de Arte da Pampulha, na época referida, década de 1960 e 1970, conhecido como Museu de Arte de Belo Horizonte. Seja pela equipe do Museu ou pelos órgãos da Prefeitura ao qual se vinculava, a documentação foi gerada nesse período e arquivada em seus espaços administrativos.

$\mathrm{Na}$ época da criação do Museu, em 1957, as políticas públicas culturais em Belo Horizonte eram gerenciadas pelo então Departamento de Educação e Cultura - DEC, que se encarregava de administrar os Salões de Artes. Em 1967, foi criada a Secretaria de Educação e Cultura, vínculo que permaneceu até 1973, quando foi criada a Secretaria Municipal de Cultura, Informação, Turismo e Esportes. Esta Secretaria realizava o controle administrativo de todos os museus municipais. Em 1983, em nova reformulação, a Secretaria passou a ser somente de Cultura e Turismo, mantendo o Museu de Arte de Belo Horizonte sob sua subordinação. Somente em 1989 a cultura passou a ter pasta exclusiva de uma secretaria específica, mantendo a subordinação do MABH com "status" de $3^{\circ}$ nível na escala hierárquica da estrutura administrativa da prefeitura, o que durou até 2005, quando foi transformada em Fundação Municipal de Cultura.

Esse histórico institucional é importante para compreendermos os tramites ligados à produção dos documentos analisados nas pesquisas. Somente com esta análise foi possível compreender porque os documentos relativos aos Salões encontram-se guardados no APCBH e não no MAP. Para um pesquisador leigo que siga a lógica da pesquisa documental simplesmente por sua origem de produção, isso poderia criar graves problemas de lacunas. Por isso é tão importante compreendermos a circulação dos documentos, o seu processo de acondicionamento e as responsabilidades de cada órgão na preservação desta memória. Isso tudo para que não consideremos, precipitadamente, as lacunas como estando relacionadas à extravios ou inexistências de documentos que são citados em outras fontes ou referendados pelas práticas museológicas.

Em 1993 um lote de documentos relativos aos Salões foi transferido do MAP para o APCBH. Isso porque pela organização administrativa vigente à época, determinou-se que o órgão responsável pela guarda da documentação do MAP fosse o Arquivo Municipal. Em Decreto Municipal n 9.223, de 20.05. 1997, essa prática foi reafirmada, determinando a transferência de dossiês de eventos ocorridos no Museu ao arquivo permanente do APCBH, após o prazo de seis anos nos arquivos correntes. De documentos relativos aos salões, restaram no MAP apenas os cadernos de atas dos júris. $\mathrm{Na}$ apresentação dos documentos no catálogo de consultas do APCBH"', é informado que

Não foi possível apurar se houve, antes da transferência, veto à remessa ao Arquivo de algum tipo de documento a partir de critérios de seleção estabelecidos na fonte produtora. Não obstante, durante o processo de arranjo, foi detectado um alto grau de organicidade no acervo tendo sido eliminados, genericamente, exemplares repetidos de diversos documentos, cópias reprográfi-

" http://www.acervoarquivopublico.pbh.gov.br/acervo.php?cid=18 
cas esmaecidas, capas de papelão e envelopes. (ARQUIVO PÚBLICO DA CIDADE DE BH, 2017)

Em certa medida esta afirmação nos ajuda a compreender porque documentos relativos à material de divulgação, tais como, catálogos e convites encontram-se também guardados em cópias originais no Centro de Documentação do Museu. Podemos então supor que houve sim uma separação e organização dos documentos antes da entrega definitiva, deixando no local de origem cópias consideradas relevantes e representativas para a história do evento dentro da instituição.

Nessa remessa do MAP para o APCBH, considerou-se o remetente como unidade externa da Secretaria da Municipal de Cultura, sendo por isso o acervo tratado pelo órgão de memória como subfundo dessa secretaria. Sendo assim, seus acervos documentais, com destinação à guarda permanente, são classificados em séries e subséries com base na funcionalidade tipológica de seus documentos. $O$ acervo que foi fotografado e organizado pelo Grupo MAV, é constituído de dossiês relativos a eventos, no caso os Salões de Arte, sendo estes agrupados nas séries "Dossiês dos Salões Municipais de Belas Artes" e "Dossiês dos Salões Nacionais de Arte da Prefeitura de Belo Horizonte". Essa mudança de nomenclatura corresponde à mudança no nome do evento que em 1969 passou à alcunha de Nacional.

Com todo o material coletado, foi preciso analisar as imagens feitas e assim buscar, ao máximo possível, qualidade técnica e nitidez visual, com resolução fotográfica capaz de gerar ampliações para fácil leitura e percepção de detalhes das imagens. Esse cuidado foi crucial, já que as imagens são a base de toda a formulação deste acervo, sendo desenvolvido através delas todos os dados gerados nesta base. Um ponto importante no processo de análise das fontes encontradas, foi o cuidado com o manuseio dos documentos originais acessados nas instituições de memória, o que nos despertou para a realidade do risco das perdas (encontramos papéis muito fragilizados pelo tempo) e da relevância da guarda digital das informações.

Referente a essa primeira iniciativa do projeto, Vera Dodebei considera o ato de transformar um documento em arquivo digital e a partir disso criar e manusear uma memória digital, de grande importância para a preservação da memória. Preservar em meio digital contribui para a preservação do conteúdo intelectual,"preservar então significa reter significados de modo a que se possa recriar a forma digital ou a função do objeto para assegurar sua autenticidade e acessibilidade". (DODEBEI: 2006: 9).

A segunda fase do projeto diz respeito à organização dessas fontes, que é feita online e utilizando site com armazenamento em nuvem ${ }^{12}$. Como critério de organização os documentos foram então separados a partir do ano de cada Salão. Esse evento gerava uma série de documentos, produzidos pela própria instituição museológica e seus órgãos públicos da Prefeitura vinculados, ou por outros meios de comunicação, sendo o principal, jornais da época.

Com uma variedade de tipologias de fontes, houve uma divisão por pastas, que foram nomeadas de acordo com o agrupamento desses tipos: "catálogo", "documentação administrativa", "fontes jornalísticas" e ainda, um arquivo gerado com o registro das principais informações sobre cada Salão. Dentro de cada uma dessas divisões, foi necessário criar alguns critérios para que se formasse

\footnotetext{
${ }^{12}$ Google Drive. - serviço que permite o armazenamento de arquivos na nuvem do Google. Estes arquivos podem ser compartilhado entre colaboradores através de uma conta do Google sendo possível gerenciar o nível de acesso de cada pessoa entre visualização, edição e comentários.
} 
um sistema coerente com todos os dados. No ano de 1977, as fotografias foram feitas como recortes, assim, as datas das reportagens estão em imagens separadas das fontes. Por esse motivo, foi adotado o critério de aceitar que a sequência das imagens determina sua data e para aquelas imagens que não possuem data, foi criada a pasta "sem referência".

A organização das fontes nos proporcionou a análise do perfil e de certas recorrências no conteúdo das fontes. Por exemplo, em relação aos jornais de circulação na época, os que mais divulgaram os Salões foram: Diário da Tarde, com I44 reportagens; o Estado de Minas, com 93; e o Diário de Minas, com 34. É interessante notarmos que, além desses, muitos jornais de fora do estado de Minas Gerais contribuíram com divulgações e notícias sobre o evento, mesmo de forma reduzida, podendo ser citados nesse contexto, O Estado de São Paulo e o Jornal do Brasil. Isso, portanto, demonstra não só o alcance dos Salões de Arte, como também a movimentação no circuito artístico nacional.

Na categoria "documentação administrativa" encontramos fatos pontuais e institucionais sobre os eventos estudados, sendo estes de perfil mais variado e conteúdo diverso. Neste tipo, infelizmente, não foi possível encontrar para todos os anos a mesma disponibilidade de documentos que nos ofereceriam informações mais precisas sobre os artistas participantes e sua forma de atuação nos Salões já que são raras as fichas de inscrição, registros do número de inscritos, lista de artistas selecionados, registros de fretes e recibos de obras.

Percebemos que as publicações dos jornais que abordavam os salões, tinham um perfil de conteúdo muito similar. Geralmente, a partir dos meses de outubro e novembro de cada ano, eram publicadas matérias sobre os preparativos para a realização dos Salões e as regras para as inscrições. Entre as últimas semanas do mês de novembro até a primeira semana de dezembro, as matérias divulgavam os componentes do júri, os artistas participantes, as críticas aos regulamentos, os resultados e os comentários críticos sobre os resultados. Nas vésperas de abertura dos Salões as matérias anunciavam o evento como parte da programação das comemorações de aniversário da capital mineira, sempre realizada no dia 12 de dezembro, quando a exposição era inaugurada com a presença de autoridades políticas, artistas e sociedade civil.

Já nos catálogos, todos encontrados no APCBH, o valor informacional que se adquire ao buscá-los e preservá-los está relacionado ao acesso às informações sobre a exposição, o regulamento, a lista de obras, os membros do júri, lista de premiados, textos referentes à exposição e objetivos do Salão e, as vezes, as imagens das obras. As mudanças no formato dos catálogos, tipo de conteúdo e extensão das informações, poderão ser analisadas em contrapartida com informações sobre a história do Museu, tendo como foco de pesquisa, questões relativas ao perfil institucional em diferentes momentos.

Em uma terceira fase do processo, os arquivos gerados para registro de informações foram ampliados, como forma de sistematizar as principais informações das fontes citadas associando-as às imagens das obras presentes no acervo do Museu de Arte da Pampulha. Sua composição é padronizada e segue os seguintes itens:0I) Considerações sobre o Salão: fontes jornalísticas transcritas que refletem a recepção da crítica sobre o Salão daquele determinado ano; 02) Apresentação do Júri com os nomes dos participantes daquele ano;03) Lista de artistas premiados; 04) Informações sobre o artista e obra premiada como por exemplo nome e biografia do artista, comentário crítico, levantamento bibliográfico, obras anteriores, obra(s) premiada(s), descrição da obra premiada.

Por último, foi criado um sistema de organização que permite ao pesqui- 
sador buscar em uma lista de referências aquela fonte documental que se tem interesse. A partir do link criado nessa lista, dá-se acesso à imagem do documento e sua transcrição na íntegra. As matérias jornalísticas de conteúdo mais relevante, por conter comentários sobre as obras, sobre os artistas e críticos ou sobre aspectos relativos ao Salão, foram transcritas na íntegra, armazenadas juntamente com as imagens da página do jornal fotografada, sendo também acessada por link na lista das referências. Essas transcrições estão disponíveis junto às suas reportagens na pasta "fontes jornalísticas".

O trabalho de organização de fontes documentais se relaciona diretamente à conscientização da importância da preservação e valorização dos acervos artísticos presentes nos museus de Belo Horizonte. Enquanto objetos de pesquisa as obras de arte nos trazem novos questionamentos que nos conduzem à busca de outras fontes. Mesmo que em certa medida sejam estabelecidas hierarquias de importância, dada a sua relevância de origem das informações e aproximações com o objeto de pesquisa, todas as fontes documentais são importantes, precisam ser consultadas e questionadas. Por isso sua organização, como primeiro passo na metodologia de pesquisa, é essencial para uma condução segura dos estudos, evitando-se assim a reprodução de discursos pré-estabelecidos que não levam em conta os confrontos necessários para se colocar a prova os vários testemunhos da história da arte.

\section{Conclusão}

A importância de projetos que organizam fontes documentais está ligada à possibilidade de diferentes estudos relacionados ao que podemos chamar de tipologia das fontes. Essa tipologia no campo das artes abrange as críticas ao "calor da hora", o estudo da história das exposições, a escrita sobre os artistas e os variados registros documentais que versam sobre a trajetória de existência das obras e dos agentes que transitaram no circuito artístico em que ela se insere. O Acervo Documental dos Salões de Arte de Belo Horizonte e o Banco de Dados do Inventário do Museu de Arte da Pampulha são ferramentas que possibilitam o acesso às fontes em suas diferentes tipologias, uma vez que trazem a localização e conteúdo dos registros históricos das obras e da instituição.

$\mathrm{Na}$ análise de fontes feitas pelo historiador da arte é de fundamental importância o conhecimento da origem das fontes para que os sujeitos e suas narrativas sejam questionados. $O$ conhecimento aprofundado das fontes contribui para uma narrativa coerente, no que tange a historicidade do recorte temporal e espacial estabelecido na pesquisa, evitando-se erros relacionados aos anacronismos e julgamentos equivocados.

Há entre essas duas ferramentas de pesquisa criadas a possibilidade do cruzamento de informações e de checagem para confirmações na contraposição de fontes. $\mathrm{Na}$ tentativa de esgotarmos o rastreamento dos documentos e a sistematização das informações, percebemos que o trabalho com o Banco e com o Acervo leva o pesquisador a elaboração de novos questionamentos, conduzindo-o a busca de outras fontes de pesquisa que ainda possam existir fora dos limites das instituição de guarda dos documentos levantados.

$\mathrm{Na}$ análise das fontes disponibilizadas no Acervo Documental dos Salões de Arte de Belo Horizonte é possível resgatar informações institucionais sobre esses eventos ocorridos no Museu de Arte da Pampulha. No cruzamento destas informações em consulta ao Banco de Dados do Inventário do Museu de Arte da Pampulha, é possível identificar a participação e produção de artistas que 
OAcervo documental e inventário de obras do Museu de Arte da Pampulha, possibilidades de escrita da História da Arte

estiveram nos Salões em determinado período. Se no banco, a busca está mais relacionada à informações técnicas como datas, nomes de artistas e obras, no Acervo Documental encontramos dados que contextualizam tais informações. O trabalho conjunto das duas ferramentas abre o debate sobre o que foram os Salões de Arte no Museu da Pampulha e também para outros recortes temáticos de pesquisa.

\section{Referências}

DODEBEI, V. Patrimônio e memória digital. Morpheus: Revista Eletrônica em Ciências Humanas. Rio de Janeiro, v. 4, n. 8, p. I-I4, 2006.

Inventário - Museu de Arte da Pampulha / Museu de Arte da Pampulha. -- Belo Horizonte: Museu de Arte da Pampulha, 2010.240 p.

OLIVEIRA, Emerson Dionísio Gomes de. Museus de fora: a visibilidade dos acervos contemporâneos no Brasil. Porto Alegre: Zouk, 2010.

PADILHA, Renata Cardozo. Documentação Museológica e Gestão de Acervo. Florianópolis: FCC, 20I4. (Coleção Estudos Museológicos, v.2)

SANTOS, Nelyane. Metodologia de pesquisa da história da arte para o estudo de obras dos Salões Municipais de Belas Artes de Belo Horizonte na década de 1960. Anais eletrônicos do XX Encontro Regional de História da ANPUH-MG, “História em tempos de crise", 2016, Uberaba. Disponível em http://encontro2016.mg.anpuh.org/resources/anais/44/1469226038_ARQUIVO_ARTIGO-ANPUH-2016-NELYANE.pdf.Acessado em 30 maio de 2017.

VIVAS, Rodrigo. Museu Revelado: o fardo da história não revelada. In: Museu Revelado. I ${ }^{a}$ ed. Belo Horizonte: Prefeitura Municipal de Belo Horizonte, 2013.

VIVAS, Rodrigo; GUEDES, Gisele. Desejos individuais - imagens de coletividade. Ouvirouver. Uberlândia, v. I2, n I, p. 168-179, 2016.

VIVAS, Rodrigo; GUEDES, Gisele. Da Narrativa Comum à História da Arte: Uma Proposta Metodológica. Art Sensorium - Revista Interdisciplinar Internacional de Artes Visuais. Paraná, vol. 2, nI, 2015.

YASSUDA, Nathaly Silvia. Documentação Museológica uma reflexão sobre o tratamento descritivo do objeto no Museu Paulista. Marília: Unesp, 2009.

Endereços eletrônicos

SIQUARA, Carlos Andrei. Acervo do MAP em livro. O tempo, Belo Horizonte, 8 mar. 20I I. Disponível em <http://www.otempo.com.br/pampulha/acervo-do-map-em-livro-I.8978>.Acesso em I5 jun. 2016

ARQUIVO PÚBLICO DA CIDADE DE BELO HORIZONTE. Fundos e Coleções. Belo Horizonte, 20 I7. Disponível em <http://www.acervoarquivopublico. pbh.gov.br/acervo.php?cid=|83>. Acesso em 30 mai. 2017. 